\title{
Etiology of Portal Hypertension in Children-An Experience in a Tertiary Centre of Bangladesh
}

\author{
SALAHUDDIN MAHMUD ${ }^{1}$, SYED SHAFI AHMED ${ }^{2}$, JAHIDA GULSHAN ${ }^{3}$, FARHANA TASNEEM ${ }^{4}$
}

\begin{abstract}
Background: Portal hypertension is defined by a pathological increase in portal venous pressure. Any condition that interfere with blood flow at any level within the portal system can lead to portal hypertension. For better management, it is important to determine the underlying cause.

Objective: To evaluate the etiology of portal hypertension in children admitted in a tertiary care centre of Bangladesh.

Materials \& Methods: This cross sectional study was done in the Department of Pediatric Gastroenterology, Hepatology \& Nutrition, Dhaka Shishu (Children) Hospital, Dhaka, Bangladesh on 40 consecutive cases of portal hypertension enrolled from April 2014 to March 2015.

Results: Age of the children was 2-12 years with mean age of $7.2 \pm 4.3$ years and male:female ratio was 1.5:1. Out of 40 children, 32 (80\%) developed portal hypertension due to pre-hepatic causes and 8 (20\%) hepatic causes. In pre-hepatic causes of portal hypertension, out of 32 children, portal vein thrombosis was found in 20 (62.5\%) cases, splenic vein thrombosis in 4 (12.5\%) \& 8 (25\%) were idiopathic. On the other hand hepatic causes of portal hypertension, out of 8 children, cryptogenic was found in 4 (50\%) cases, wilson's disease, chronic hepatitis B virus infection, biliary cirrhosis \& autoimmune hepatitis each was found in 1 (12.5\%) case. In pre-hepatic cases first variceal bleed much earlier than hepatic cases (4.4 $\pm 3.6 \mathrm{Vs} 7.6 \pm 4.6$ years).
\end{abstract}

Conclusion: Extra-hepatic diseases were the most common etiology of portal hypertension in studied children. Portal venous thrombosis in extra-hepatic cases \& cryptogenic liver disease in intra-hepatic cases were the most common causes.

Key words: Extra-hepatic portal venous obstruction (EHPVO), Intra-hepatic portal venous obstruction (IHPVO).

\section{Introduction}

Portal hypertension (PHT) is a clinical syndrome defined by a portal venous pressure gradient between the portal vein (PV) and inferior vena cava exceeding $5 \mathrm{mmHg}$. Cirrhotic portal hypertension is associated

1. Assistant Professor, Pediatric Gastroenterology, Hepatology \& Nutrition, Bangladesh Institute of Child Health, Dhaka Shishu (Children) Hospital

2. Professor \& Head, Pediatric Gastroenterology, Hepatology \& Nutrition, Bangladesh Institute of Child Health, Dhaka Shishu (Children) Hospital

3. Associate professor, Institute of Statistical Research and Training, University of Dhaka

4. $\mathrm{MD}$ (Paediatrics)-Final part student, $\mathrm{BICH}$

Correspondence to: Dr. Salahuddin Mahmud, E-mail: drsmbablu@gmail.com with an elevated hepatic venous pressure gradient (HVPG) predominantly due to raised sinusoidal resistance, while in the non-cirrhotic portal hypertension (NCPH), HVPG is normal or only mildly elevated \& is significantly lower than Portal Venous pressure. ${ }^{1}$ Clinically significant portal hypertension is diagnosed when clinical manifestations of the disease appear or the portal pressure gradient exceeds $10 \mathrm{mmHg}^{2}$ It can present as esophageal variceal bleeding, ascites or hypersplenism. ${ }^{3}$ The causes of portal hypertension are classified anatomically as pre-hepatic, hepatic \& post hepatic. Hepatic causes are further subdivided into presinusoidal, sinusoidal \& post-sinusoidal. ${ }^{1}$ Portal vein 
thrombosis is the predominant cause of pediatric portal hypertension in India. ${ }^{3}$ A careful investigation for the causes of the portal hypertension is essential for choosing the best treatment. ${ }^{2}$ This study was conducted to document the etiology of portal hypertension in children admitted in a tertiary care centre of Bangladesh.

\section{Materials \& Methods}

A cross sectional study was done in the department of Pediatric Gastroenterology, Hepatology \& Nutrition, Dhaka Shishu (Children) Hospital, Dhaka, Bangladesh from April 2014 to March 2015. A total of 40 admitted cases of portal hypertension between 2-16 years of age enrolled in this study after obtaining their consent.

In children, extra-hepatic portal venous obstruction (EHPVO) is defined clinically as history of hematemesis and/or malena, no history of jaundice, with or without history of umbilical catheterization or abdominal sepsis, absence of stigmata of chronic liver disease (CLD) with spenomegaly. Upper gastrointestinal endoscopy (UGI) showed esophageal varices of different grades. Doppler ultrasound also showed increase portal venous pressure with or without portal/splenic vein thrombosis.

In children, intra-hepatic portal venous obstruction (IHPVO) is defined clinically as history of jaundice and/or persistence of jaundice for more than 6 months, history of hematemesis and/or malena with presence of any stigmata of chronic liver disease (Jaundice, ascites, spider angioma, gynecomastia, caput medusae, testicular atrophy, thenar-hypothenar wasting, palmer erythema, leuconychia \& clubbing). Raised liver enzymes by liver function test (ALT, AST), increased hepatic echogenecity, irregular margins, coarse texture or nodular liver, hepato-splenomegaly with or without ascites by abdominal ultrasonogram, increase portal venous pressure by doppler ultrasound, upper gastrointestinal endoscopy (UGI) showed esophageal varices of different grades and fibrosis or nodular regeneration in liver biopsy. To find out the etiology, history of taking any offending drugs like acetaminophen, halothane, anti-inflammatory (NSAID), anti-convulsant (phenytoin, sodium valproate, carbamazepine), anti-TB (Isoniazid), antibiotics (Penicillin, erythromycin, tetracyclines, sulfonamides) etc. were taken, HBsAg, Anti-HBc total (IgM and/or IgG) , Anti-HCV antibody, HCV RNA, ANA, Anti-SMA antibody, slit lamp examination of eye (KF ring), serum ceruloplasmin, 24 hours urinary copper, penicilamine challenge test (If necessary) were done. When etiology of portal hypertension is not evident then it is called cryptogenic. $^{3}$

A preformed semi structured data collecting form was used as a data collection instrument. Data were collected by the researcher and analyzed by Statistical Package of Social Science (SPSS) version 11.5 programme. Data was analyzed by $Z$ test for proportion testing. A right tailed $p$-value of $<0.05$ was considered as significant.

\section{Results:}

All the children were between 2-12 years of age mean age was $7.2 \pm 4.3$ years. In pre-hepatic cases mean age was $4.4 \pm 3.2$ years and hepatic cases it was $6.2 \pm 4.3$ years. There were $30(60 \%)$ male \& $16(40 \%)$ female cases.

The mean age at onset of the first variceal bleeding was at $5.3 \pm 4.5$ years. In pre-hepatic cases it was $4.4 \pm 3.6$ years \& in hepatic cases it was $7.6 \pm 4.6$ years. So, in pre-hepatic cases first variceal bleed much earlier than hepatic cases.

Out of 40 children, 32 (80\%) developed portal hypertension due to pre-hepatic causes and 08 (20\%) due to hepatic causes. No patient was found with post-hepatic cause. A one sample Z-test for proportion suggested that proportion of children with pre-hepatic causes were significantly higher $(<0.001)$ than the proportion of children with hepatic cases.

Table I

Etiology of portal hypertension with significant difference

\begin{tabular}{lcc}
\hline Pre-hepatic & Hepatic & $\begin{array}{r}\text { P-value for difference } \\
\text { N }(\%)\end{array}$ \\
\hline $32(80 \%)$ & $08(20 \%)$ & $(<0.05$ significant $)$ \\
\hline
\end{tabular}

In pre-hepatic causes of portal hypertension, out of 32 children, portal vein thrombosis was found in 20 $(62.5 \%)$ cases, splenic vein thrombosis in $4(12.5 \%)$ cases \& others in 08 (25\%) cases. So, among studied children, portal vein thrombosis was the leading cause in extra-hepatic portal venous obstruction (EHPVO).

In hepatic causes of portal hypertension, out of 08 children, cryptogenic was found in $4(50 \%)$ cases, Wilson's disease, chronic hepatitis B, biliary cirrhosis and autoimmune hepatitis was found in 1 (12.5\%) case each. So, cryptogenic was the leading cause of intrahepatic portal venous obstruction (IHPVO) in studied children. 
Table II

Frequency of underlying causes of portal hypertension

\begin{tabular}{llc}
\hline $\begin{array}{l}\text { Etiology of } \\
\text { Portal Hypertension }\end{array}$ & $\mathrm{N}(\%)$ \\
\hline Pre-hepatic & Portal vein thrombosis & $20(62.5 \%)$ \\
& Splenic vein thrombosis & $4(12.5 \%)$ \\
& Others & $8(25 \%)$ \\
Hepatic & Cryptogenic & $4(50 \%)$ \\
& Wilson's disease & $1(12.5 \%)$ \\
& Hepatitis B virus & $1(12.5 \%)$ \\
& Biliary cirrhosis & $1(12.5 \%)$ \\
& Autoimmune hepatitis & $1(12.5 \%)$ \\
\hline
\end{tabular}

\section{Discussion}

Portal hypertension leads to formation of portal systemic collaterals which shunt a portion of the portal blood to the systemic circulation, bypassing the liver. Portal hypertension can arise from disorders with blood flow at any level within the portal system. 5,6

In the present study of children, mean age was $7.2 \pm 4.3$ years. Similar mean age was also observed in a study in Iran. Their mean age was $7.6 \pm 4.7 .^{2}$ In this study, mean age of pre-hepatic cases was $4.4 \pm 3.2$ years and in hepatic cases it was $6.2 \pm 4.3$ years. So, bleeding occurred in pre-hepatic cases much earlier than hepatic cases. Similar observation was also reported in North Indian children. ${ }^{7}$

Imanieh et al. ${ }^{2}$ reported that the mean age at onset of the first variceal bleeding was at $4.3 \pm 4.5$ years of age. This study also found the near similar result. The mean age at onset of the first variceal bleeding was at $5.3 \pm 4.5$ years. In pre-hepatic cases it was $4.4 \pm 3.6$ years \& hepatic cases $7.6 \pm 4.6$ years. So, in pre-hepatic cases first variceal bleed much earlier than hepatic cases.

In the current study, among total children male were 24 (60\%) \& female 16 (40\%). Male:female ratio was 1.5:1. So, portal hypertension more observed in male than female. But Imanieh et al. ${ }^{2}$ reported the different result. There ratio was 1.01:1.

Several studies have reported the pattern of portal hypertension to be different in children and adults. In adults the etiology of portal hypertension is mostly intra-hepatic, whereas the pattern is extra-hepatic in children. ${ }^{8-11}$ Several studies from India stated that the most common causes of pediatric portal hypertension were extra-hepatic portal venous obstruction. ${ }^{12,13}$ In the current study we also observed the similar result. Here, out of 40 children, 32 (80\%) developed portal hypertension due to pre-hepatic causes and 08 (20\%) were hepatic causes. Arora et al. ${ }^{7}$ also observed $76.5 \%$ cases of extra-hepatic portal hypertension in North Indian children. So, among studied children, pre-hepatic causes were significantly $(<0.001)$ higher than hepatic causes. On the other hand, Grimaldi et al. ${ }^{14}$ reported that the main causes of portal hypertension in children were cirrhosis and congenital hepatic fibrosis. Bernard et al. ${ }^{15}$ also reported that intra-hepatic potal venous obstruction (EHPVO) or cirrhosis was responsible for $51 \%$ of portal hypertension in children and extra-hepatic portal venous obstruction was found in $34 \%$ of cases. Imanieh et $\mathrm{al}^{2}$ in Iran also observed portal hypertension due to hepatic causes in $93.3 \%$ of children.

In the present study, among all children with extrahepatic portal venous obstruction, portal vein thrombosis was the leading cause. Out of 32 children, it was observed in 20 (62.5\%) cases. Podder et al. ${ }^{12}$ and Arora et al. ${ }^{7}$ also reported similar results. Other causes were splenic vein thrombosis in $4(12.5 \%)$ cases \& others in 08 (25\%) cases.

Imanieh et al ${ }^{2}$ reported that, main cause of intrahepatic portal hypertension was cryptogenic. Out of 45 children, it was observed in $12(26.7 \%)$ cases. Other causes were biliary cirrhosis 11 (24.4\%) cases, Wilson's disease $8(17.8 \%)$ cases \& congenital hepatic fibrosis $3(6.7 \%)$ cases. Similar results were observed in our study. Out of 8 children, cryptogenic were $4(50 \%)$ cases, Wilson's disease, chronic hepatitis $B$ virus infection, biliary cirrhosis and autoimmune hepatitis were observed in 01 (12.5\%) cases each. In adult, again cryptogenic was the predominant cause of intra-hepatic portal hypertension, followed by alcohol, hepatitis B \& hepatitis C virus infection. ${ }^{16,17,18}$

\section{Conclusions}

Extra-hepatic portal hypertension were the most common among studied children. Portal vein thrombosis in extra-hepatic cases \& cryptogenic in intra-hepatic cases were the most common cause. In pre-hepatic cases first variceal bleeding much earlier than hepatic cases. 


\section{Limitations of study}

Study was conducted in single centre. Multicentre study will provide more accurate information.

\section{References}

1. Khanna R, Sarin SK. Non-cirrhotic portal hypertension - Diagnosis and Management. $J$ Hepatol 2014; 60: 421-41.

2. Imanieh $\mathrm{MH}$, Dehghani SM, Khoshkhui M, Malekpour A. Etiology of portal hypertension in children: A single center's experiences. Middle East J Dig Dis 2012; 04: 206-10.

3. Goel A, Madhu K, Zachariah U, Sajith KG, Ramachandran J, Ramakrishna B et al. A study of aetiology of portal hypertension in adults (including the elderly) at a tertiary centre in southern India. Indian J Med Res 2013; 137: 92227.

4. Ling SC. Portal hypertension in children. Clin Liver Dis 2012; 1: 139-42.

5. Bosch J, Abraldes JG, Groszmann R. Current management of portal hypertension. $J$ Hepatol 2003;38 (Suppl 1): S54-68.

6. Bargalló X, Gilabert R, Nicolau C, García-Pagán JC, Bosch J, Brú C. Sonography of the caudate vein: value in diagnosing Budd-Chiari syndrome. Am J Roentgenol 2003;181: 1641-5.

7. Arora NK, Lodha R, Gulati S, Gupta AK, Mathur $\mathrm{P}$, Joshi MS et al. Portal hypertension in North Indian children. Indian Pediatr 1988; 65: 585-91

8. Ekhauser F, Appelman H, Knol J, Strodel W, Coran A, Tur-cotte J. Noncirrhotic portal hypertension: Differing patterns of disease in children and adults. Surgery 1983;94: 721-8.

9. Ando H, Kaneko K, Ito F, Seo T, Watanabe $\mathrm{Y}$, Ito T. Anato-my and etiology of extra- hepatic portal vein obstruction in children leading to bleeding esophageal varices. J Am Coll Surg 1996;183: 543-7.
10. Yachha S, Khanduri A, Sharma B, Kumar M. Gastro-intestinal bleeding in children. J Gastroenterol Hepatol 1996;11: 903-7.

11. Ryckman FC, Alonso MH. Causes and management of portal hypertension in the pediatric population. Clin Liver Dis 2001; 5(3): 789-818.

12. Simon EG, Joseph A, George B, Zachariah UG, Jeyamani R, Eapen $C$, et al. Aetiology of paediatric portal hypertension - experience of a tertiary care centre in South India. Trop Doct 2009; 39: 42-4.

13. Poddar U, Thapa BR, Rao KLN, Singh K. Etiological spectrum of esophageal varices Due to portal hypertension in Indian children: Is it different from the West? J Gastroenterol Hepatol 2008; 23: 1354-7.

14. Grimaldi C, de Ville de Goyet J, Nobili V. Portal hypertension in children. Clin Res Hepatol Gastroenterol 2012;36: 260-1.

15. Bernard O, Alvarez F, Brunelle F, Hadchouel P, Alagille D. Portal hypertension in children. Clin Gastroenterol 1985;14: 33-55.

16. Michitaka K, Nishiguchi S, Aoyagi $\mathrm{Y}$, Hiasa $\mathrm{Y}$, Tokumoto Y, Onji M. Japan Etiology of Liver Cirrhosis Study Group. Etiology of liver cirrhosis in Japan: a nationwide survey. J Gastroenterol 2010; 45: 86-94.

17. Mendez-Sanchez N, Aguilar-Ramirez JR, Reyes A, Dehesa M, Juorez A, Castneda B, et al. Groupo de Estudio, Asociaon Mexicana de Hepatologyia. Etiology of liver cirrhosis in Mexico. Ann Hepatol 2004; 3: 30-3.

18. Johnson EA, Spier BJ, Leff JA, Lucey MR, Said A. Optimising the care of patients with cirrhosis and gastrointestinal haemorrhage: a quality improvement study. Aliment Pharmacol Ther 2011;34: 76-82. 